\title{
Advancing Access to Higher Education for Students with Intellectual Disability in the United States
}

\author{
Meg Grigal ${ }^{1}$, Lyman L. Dukes III ${ }^{2}$ and Zachary Walker ${ }^{3, *}$ \\ 1 Institute for Community Inclusion, University of Massachusetts Boston, Boston, MA 02125, USA; \\ Meg.Grigal@umb.edu \\ 2 Education Studies, College of Education, University of South Florida, St. Petersburg, FL 33701, USA; \\ LDukes@usf.edu \\ 3 Institute of Education, University College London, London WC1H 0AL, UK \\ * Correspondence: zachary.walker@ucl.ac.uk
}

Citation: Grigal, M.; Dukes, L.L., III; Walker, Z. Advancing Access to Higher Education for Students with Intellectual Disability in the United States. Disabilities 2021, 1, 438-449. https://doi.org/10.3390/ disabilities1040030

Academic Editors: Janet Finlayson and Stuart Todd

Received: 21 September 2021 Accepted: 8 November 2021 Published: 16 November 2021

Publisher's Note: MDPI stays neutral with regard to jurisdictional claims in published maps and institutional affiliations.

Copyright: (C) 2021 by the authors. Licensee MDPI, Basel, Switzerland. This article is an open access article distributed under the terms and conditions of the Creative Commons Attribution (CC BY) license (https:/ / creativecommons.org/licenses/by/ $4.0 /)$.

\begin{abstract}
Due to changes in legislation and policy in the United States, higher education has become more available to people with intellectual disability (ID). Currently, over 6000 students with ID are enrolled in 310 colleges and universities. In the past decade, the federal government has invested over 100 million dollars in a model demonstration program aimed at institutions of higher education to create, expand, or enhance high-quality, inclusive higher education experiences to support positive outcomes for individuals with ID. This article will describe the impetus and impact of this funding as well as related changes in policy and practice. With the emergence of these opportunities, a field of research has emerged, offering new knowledge about what higher education can offer to students with ID as well as the positive impact these students have on their peers, professors, and campus communities. We have also begun to see documentation of more long-term impacts of higher education on students' employment, independent living outcomes, and life satisfaction. By describing these policy, practice, and research developments, this article will provide readers with a better understanding of the background, current status, and future needs of the field of inclusive higher education for people with ID in the United States and potential takeaways for similar stakeholders in other countries.
\end{abstract}

Keywords: intellectual disability; higher education; transition

\section{Introduction}

The impact of postsecondary education (PSE) on positive adult outcomes in the United States (US) is well documented, resulting in higher rates of employment and improved earnings regardless of disability status [1]. A recent study reported that median earnings increase with each additional level of education: a person who earns a high school diploma has a median income of $\$ 36,000$, whereas the median income of a person with a bachelor's degree is $\$ 62,000$ and $\$ 80,000$ for a person with a graduate degree [2]. The impact of higher education on employment and earnings is forecasted to remain strong, with the Georgetown University Center on Education and the Workforce predicting $70 \%$ of all jobs will require some education beyond high school by 2027 [3]. The employment rates of individuals with disabilities, including those with intellectual disability, have also been linked to access to higher education [4]. Historically, students with intellectual disability (ID) have the lowest rates of engagement in postsecondary education or work or after high school compared to students with other disabilities $[5,6]$.

Fortunately, PSE access for students with ID has increased in recent years [7], with increasing numbers of students enrolling in PSE experiences leading to competitive integrated work opportunities. In 2010, prior to the expansion of participation in PSE among students with ID, Southward and Kyzar [8] reported the unemployment rate of individuals with ID was $85 \%$. Of those who were employed, only $48 \%$ earned a competitive wage. 
In contrast, Miller and colleagues [9] reported people with intellectual or developmental disability (IDD) who participated in a PSE certificate or degree program had wages of nearly $\$ 18,000$ annually as compared to slightly more than $\$ 10,000$ per year for those not participating in PSE. Even with these obvious benefits, significant barriers remain to promoting and providing access to PSE for students with IDD [10].

While employment is necessary for financial independence, employment also adds value to the lives of people with disability in other ways [11]. For example, employment can lead to the development of relationships and positive feelings of self-worth [12]. Similarly, the importance of participation in PSE for students with ID extends beyond academic inclusion and provides the opportunity to participate in campus social activities such as campus clubs and the option of living in campus residence halls. Participation in PSE also has several benefits beyond employment and social integration. Butler et al. [11] found students with ID enrolled in PSE reported better physical health, healthier relationships, and higher rates of volunteerism as compared to a control group not enrolled in higher education. For example, the authors found $73 \%$ of students in PSE had exercised recently compared to $37 \%$ of the young adult group not participating in higher education. Approximately $83 \%$ of the student group had friendships and companionship while $54 \%$ of the young adult group reported the same. Finally, two-thirds (66.7\%) of students volunteered, while only $24.3 \%$ of the young adult group did volunteer work.

Given the reported benefit of PSE experiences, there is significant potential for increased participation in PSE for youth and adults with ID. In the US, over 6000 students with ID have enrolled in higher education. Yet, only $4 \%$ of Institutes of Higher Education (IHEs) in the US currently provide this opportunity [13]. To support future development and expansion efforts of inclusive PSE worldwide, the authors will describe the legislation, policy and practice changes that have led to the current status of PSE offerings in the US for students with ID and their associated impacts on students and systems.

It should be noted not all PSE programs being accessed by students with ID can be described as inclusive. Some programs attended by students with ID may use non-inclusive or segregated environments and offer only specialized curricula separate from traditional college options including separate courses, clubs, and workshops only for students with ID. According to Jones et al. (2015), an inclusive campus "generates natural supports within the community to meaningfully involve all students in campus life. It provides students with disabilities the same opportunities and choices available to those without disabilities, never relegating students with ID to separate or segregated experiences" [14] (p. 2). Therefore, in this article, we will use the term inclusive PSE when referring to the field of study seeking to explore and build college and university programs and practices that include students with ID in the living, learning, and working environments used by their college peers without ID.

\section{History of the Development of Inclusive Postsecondary Education in the United States}

While the practice of providing PSE access to students with ID in the US remains relatively limited in scope, the idea first emerged in the 1970s due to a variety of movements primarily focused on adult education [15]. For example, Jones and Moe described the benefits of providing further education for individuals with ID so they could prepare for careers, obtain a basic education, or "simply because it seems like the thing to do for young adults" [16] (p. 59). In the late 20th century and first decade of the 21st century, program development efforts expanded to include providing access to college experiences for students with ID transitioning out of high school and during early adulthood [17]. However, there was no federal or state guidance or funding available to support these efforts; thus, early programs were funded by grants or by fundraising efforts by parents or non-profit organizations [18]. Programs varied widely in terms of their focus and activities, and little was known about student outcomes [17]. The first federally funded national survey of existing higher education programs serving students with ID in the US was conducted in 2009 and resulted in the identification of 149 higher education programs 
supporting students with ID in 39 states [19]. The findings from this survey provided a baseline of information on the types of colleges and universities involved and revealed the primary focus of most programs was independent living/life skills, not academic access. This would soon begin to change because of the reauthorization of federal higher education legislation.

\section{Impact of Legislation}

The Higher Education Opportunity Act (HEOA) (Public Law (PL) 110-315) [20] passed by the United States Congress in 2008 reauthorized the Higher Education Act of 1965 (PL 89-329) [21] and had a significant impact upon postsecondary access for students with ID [13]. For example, the HEOA requires programs receiving federal funding to ensure students with ID have the opportunity to participate on more than a half-time basis as determined by the institution, with such participation focusing on academic components, and occurring through one or more of the following activities:

- Regular enrollment in credit-bearing courses with non-disabled students offered by the institution.

- Auditing or participating in courses with non-disabled students offered by the institution for which the student does not receive regular academic credit.

- $\quad$ Enrollment in non-credit-bearing, non-degree courses with non-disabled students.

- Participation in internships or work-based training in settings with non-disabled individuals.

Additionally, the law requires students with ID to be socially and academically integrated with non-disabled students to the maximum extent possible.

The HEOA defined the term intellectual disability as a student: (A) with a cognitive impairment, characterized by significant limitations in (i) intellectual and cognitive functioning and (ii) adaptive behavior as expressed in conceptual, social, and practical adaptive skills; and (B) who is currently, or was formerly, eligible for a free appropriate public education under the Individuals with Disabilities Education Act (PL 105-17) [22]. Second, the HEOA created a new Title IV eligibility category called Comprehensive Transition and Postsecondary Programs, allowing IHEs that meet regulatory requirements to offer federal financial aid including Federal Pell grants, Federal Supplemental Educational Opportunity Grants, and Federal Work Study funding to eligible students with ID [23]. Third, HEOA modified requirements previously in place for students to access financial aid including the requirement that students obtain a high school diploma or a General Education Development (GED) degree. Finally, the HEOA also authorized and appropriated financial support for a national coordinating center for inclusive PSE program development and guidance and fiscal support of inclusive PSE model demonstration projects.

In addition to the HEOA, other federal civil rights legislation also impact access to PSE for students with disabilities. Section 504 of the Rehabilitation Act of 1973 (PL 93-112) [24], the Americans with Disabilities Act (ADA) of 1990 (PL 101-336) [25] and the more recent ADA Amendments Act (ADAAA) passed in 2008 (PL 110-325) [26] have long prevented discrimination by colleges and universities receiving federal funding (e.g., institutions that accept federal financial aid). Section 504 ensures people with disabilities have the opportunity to participate in or benefit from federally funded programs while being protected from discriminatory practices. That is, postsecondary institutions may not discriminate in the recruitment, admission, or access to programs and services for enrolled students. The ADAAA ensures students with disabilities are provided equal educational opportunity. For example, students with disabilities may be provided auxiliary aids and services to have an equal opportunity to participate in PSE.

In addition to federal legislation, some states in the US have formalized policies and practices and, in a few cases, passed legislation (e.g., Florida); all of which are intended to increase access to PSE. In the US, Vocational Rehabilitation (VR) helps people who have disabilities engage in employment. The VR program in the US is a federally funded, state-operated system providing vocational and rehabilitative services to individuals with disabilities to help them prepare for, secure, regain or retain employment. As will later be 
described, individuals with ID who engage with VR services and participate in PSE are far more likely to be employed than those who did not access them [27].

\section{Outcomes of the Higher Education Opportunities Act on the Field of Inclusive PSE}

As noted, HEOA established funding for the Transition Postsecondary Programs for students with intellectual disabilities (TPSIDs) and its related national coordinating center (NCC). Indeed, it has had a significant impact on both students with ID and the IHEs that have chosen to offer PSE to the population. A summary of the TPSID model demonstration program as well as the efforts of the NCC will be described next.

To date, the TPSID model demonstration program has funded three cohorts of grantees, each at an IHE. The first cohort funded 27 IHEs in 23 states between 2010 and 2015. The second cohort, comprising 25 IHEs in 19 states, received grants from 2015 to 2020 . The third and current cohort of grantees were funded between 2020 and 2025 to IHEs in 16 states. In total, the TPSID initiative has funded 74 grants in 34 states between 2010 and 2020. Many grantees worked to establish programs not only at their host IHE, but developed consortia structures, establishing programs at other IHEs in their states by providing funds and technical assistance. As of July 2021, these efforts have led to the creation or expansion of higher education programs at 119 college or university campuses in the US enrolling over 4500 students with ID.

The corresponding NCC project was awarded to Think College at the Institute for Community Inclusion at the University of Massachusetts Boston. Think College is a technical assistance, research and evaluation center which oversees a variety of grant funded projects each dedicated to developing, expanding, and improving research and practice in higher education for students with ID. The NCC was first established in 2010 with funds from the US Office of Postsecondary Education and was refunded in 2015, and again in 2020 in conjunction with funding for each subsequent TPSID cohort. The NCC was charged by the Office of Postsecondary Education with conducting an evaluation of the TPSID projects and with providing technical assistance and training to colleges and universities, K-12 local education agencies (LEAs), families and students, and other stakeholders interested in developing, expanding, or improving PSE for people with ID in the US. The NCC has developed and disseminated materials and resources to thousands of families, students, and professionals to support development and expansion of higher education pathways for students with ID.

The NCC was also charged with developing and implementing a valid framework to evaluate the TPSID model demonstration projects. The NCC created the Think College Data Network for this purpose, reflecting variables across all domains of practice (academic, social, independent living, career) TPSID grant recipients are required to address. This system has been used to collect required data from all TPSID funded programs since 2011 and now provides a comprehensive dataset of the characteristics of college students with ID as well as their experiences and outcomes. Data on student demographics, college course enrollments, academic supports, career development and employment and exit status are gathered annually in the system. These data are subsequently used to produce annual reports sharing aggregate data on student activities and outcomes [28]. Additionally, the NCC collaborates with all grantees to gather follow-up data from students who have exited the TPSID programs to document long-term employment and independent living outcomes.

Data derived from the IHEs receiving TPSID funds document the achievements of students attending these programs. Since the inception of the TPSID program, the NCC has documented students with ID were enrolled in 51,112 courses and held 2154 individual paid jobs. Inclusion in typical university courses is a hallmark of the program, and the TPSIDs are charged with expanding access to existing university coursework, career services, student participation in campus organizations and activities, and, when available, campus housing. Inclusive courses are defined as academic courses taught by faculty as part of the typical course offerings of the college or university and attended by matriculating 
students [29]. Depending upon the PSE program, students with ID may access inclusive courses either for credit or audit.

It should be highlighted that inclusion in typical coursework results in a variety of positive outcomes. First, it exposes students to a significant and meaningful array of course content and offers the opportunity to connect with college peers with or without disabilities. It may provide students with the potential to earn college credit and influence their capacity to obtain credentials or certificates. The most recent findings reflect marked growth in academically inclusive courses, with $62 \%$ of student enrollments being in inclusive college and university classes [28]. The counterpart to inclusive courses are specialized courses, designed for and attended only by students with ID. This course participation method has been utilized by PSE programs that are not fully inclusive and is not considered the most efficacious method of providing a college academic experience for students with ID.

The employment outcomes of the students enrolled in the IHEs receiving funds under the TPSID program are quite promising. The percent of students with ID employed for pay (defined as being paid by the employer at or above minimum wage) while enrolled in the TPSIDs have ranged from $43 \%$ to $53 \%$, striking in its similarity to the rate of employment for the average full-time undergraduate students while enrolled, which is $43 \%$ nationally [30]. Thus, the employment rate of students with ID while enrolled in college is at a minimum commensurate, and in some cases exceeds the employment rate of their student counterparts without ID.

\section{The Impact of Longer-Term Higher Education Access}

The potential impact of access to higher education on employment outcomes is even more striking when we examine the employment rate of youth and adults with ID being served outside of the higher education system. In 2018, 78.9\% of people with ID were being served in facility-based and non-work settings [31]. Indeed, this sobering statistic highlights that most adults with ID in the US spend their day in segregated settings only interacting with other people with ID. In the period 2018-2019, only $19 \%$ of adults with developmental disabilities in the general population had a paid job in the community [32]. The employment rate for transition-age individuals with cognitive disability (ages 16-21) was $20 \%$, or less than half the employment rate for same-age people without disabilities [31].

Fortunately, the long-term employment outcomes of students completing their higher education in programs funded by the TPSID initiative reflect a stark contrast to these dismal outcomes. One year after exiting from their TPSID IHE program, 59\% of students were employed, and $66 \%$ were employed after two years. Three years after exit, $67 \%$ reported having a paid job [28]. While the number of respondents declined in each subsequent year after exit, these findings reflect significantly better employment outcomes for students who have attended PSE than those who have not done so. These findings align with results stemming from research conducted on adults with ID receiving services from VR. Smith et al. [33] explored the outcomes of youth with ID who exited VR services under an individual plan for employment. They found those who had received PSE services as part of their plan were $14 \%$ more likely to exit with paid integrated employment and earned $51 \%$ higher wages than those who did not access PSE services. A similar study found VR clients with ID who experienced PSE were more than twice as likely to be employed and had increased earnings compared to their counterparts who did not have access to PSE while receiving VR services [27].

Other data also reflect a positive impact on students' independent living outcomes and social life satisfaction. Data from the 2019-2020 annual report on students attending TPSID programs reflect an increase in the percentage of students not living with their family [28]. In fact, more than half (53\%) of respondents indicated they were not living with family one year after exiting their higher education program, up 20\% from the previous year. Increases were also seen in the two-year outcome data. This appears to indicate, over time, students with ID become more capable of living independently, much like their young adult counterparts without disability. Additionally, greater numbers of students 
engaged in obtaining further PSE $(n=53)$ one year after exit, and most respondents $(92 \%)$ reported they were satisfied or very satisfied with their social life.

While the data from the TPSID programs offer great insight into what is possible when students with ID are afforded access to higher education, it is important to point out these data do not represent the full picture of PSE options in the US. The programs funded as TPSIDs represent only approximately one-third of the 310 higher education options available to students with ID in the US. A recent study of the entire milieu of programs revealed over 6090 students with ID were enrolled in IHEs in the US and all but one state in the US has a PSE program [29]. In fact, there has been significant growth in available options between 2009 and 2019. The previously mentioned national survey conducted in 2009 identified 149 programs existing in the US [19], while a more recent study conducted in 2019 found 274 programs, reflecting an 84\% increase since 2009 [29]. A national directory of existing programs for students with ID reflects, as of August 2021, 310 IHE programs in 49 states in the US; however, this number fluctuates with some frequency. There is currently only one state in the US not reflected in the directory (i.e., Wyoming).

Expanding access to higher education has not only led to changes in student experiences, but it has also led to changes in the infrastructure of higher education. As colleges and universities seek to develop new postsecondary options, significant planning must occur, especially for IHEs seeking to create inclusive access throughout their campuses. Successful planning requires engagement throughout the campus including administrative leadership (e.g., President, Provost, and Chancellor), as well as financial, academic and student services (e.g., bursar/office of financial aid, health services university housing, disability services, student advising, academic departments, faculty, and staff) [34]. When planning, designing, and promoting PSE programs for students with ID, it is critical to inform institutional leadership and other administrative academic and student support personnel about the benefit such PSE programs offer to the students with ID as well as to the campus community and culture. Moreover, providing examples of effective program implementation and quality student and institutional outcomes is warranted.

While investigating the barriers to PSE program development, Plotner and Marshall [34] found the level of support from different university entities grew over time, with less substantial support offered during planning activities, but more support being provided following program implementation. The authors posit that many of the concerns from faculty and administrators stem from lack of familiarity with program intent. Additionally, fears related to maintaining academic rigor, liability, student safety and faculty burden seem to lessen as the people involved have greater access and understanding of the program intention and the students served. Indeed, there is a significant lack of information in higher education about students with ID. As higher education leaders, as well as faculty and staff, engage with students with ID, their acceptance of these students and their support of the programs serving them typically grows.

Planning activities to develop higher education programs often lead to internal policy changes, as well as to a reduction in some attitudinal barriers that may have been more prevalent in previous years. Earlier in the development of the field of inclusive PSE, a strong concern often expressed during planning activities was the notion of faculty burden if students with ID were included in typical courses [19]. More recently, studies suggest faculty feel more positively about their experiences instructing students with ID [35,36]; however, some concerns persist. A study of faculty who had substantial experience instructing college students with ID found these faculty believed the inclusion of students with ID in their classes led to increased self-confidence for the instructors, and a greater capacity for reflecting on the range of student learning styles, educational experiences, and capabilities [35]. Notably, faculty indicated planning for the success of college learners with ID leads to meaningful reflection about their own teaching style.

There have been other additional important changes resulting from the HEOA impacting IHEs which include the expansion of access to federal student aid, increased development of available credentials, and the emergence of the need for accreditation 
standards and processes for these programs. The Act also created a new category of Title IV-eligible higher education program, called a Comprehensive Transition and Postsecondary Program (CTP) that allow eligible students with ID to access three forms of federal student aid (Federal Pell Grants, Federal Supplemental Educational Opportunity Grants, and Federal Work-Study funds) [37]. IHEs can apply to the Federal Student Aid office to be approved as a CTP by documenting how their program supports students with ID to access academic, career and technical, and independent living instruction to prepare for them for employment. CTPs also must ensure at least half of each student's program consists of coursework and other activities with students without disabilities. In the US, in the 2019-2020 academic year, 114 approved CTP programs existed, and federal student aid was offered to 628 students with ID at 88 colleges and universities [28]. One hundred and eighty-eight students $(20 \%)$ were reported to have received federal financial aid in the form of a Pell Grant while attending a TPSID program with CTP status [28]. Over 2.5 million dollars in aid was provided to students in the form of Pell grants, Supplemental Education Opportunity Grants, and Federal Work-Study. This represents a very small portion of 29.6 billion dollars offered for Pell grants made available to college students annually throughout the country, even so it is a significant shift in opportunity for students with ID pursuing higher education.

The expansion of credentials available to students with ID is also an area of growth in higher education. The IHEs involved in the TPSID program are required by their funding agent to create and offer students with ID access to meaningful credentials. These credentials are typically certificates, some having been developed specifically for the program and others offered by and approved by the host IHE. Credential attainment is critical as it bolsters students' ability to demonstrate to future employers or to future IHEs, the knowledge and skills they have attained in their program. It also requires the IHE to have considered and be held accountable for what a student will learn in their program. In fact, credential attainment has a strong correlation with employment outcomes. Grigal et al. [13] found earning a credential awarded by the IHE significantly increased the odds of having a paid job within 90 days of exit. Thus, credential development and implementation merit significant engagement of a broad array of university administrators.

The issue of accreditation for PSE programs for students with ID was first broached in the scope of work of the NCC, charging it with assembling a dedicated workgroup on accreditation. Over the past 10 years, this original workgroup, assembled in 2011, and a subsequent workgroup convened in 2016, developed model program accreditation standards and field tested these standards with PSE programs enrolling students with ID throughout the US. The final standards and the field test findings were reported to US Congress and to the US Secretary of Education [38]. The most current iteration of the workgroup, convened in 2020, is focusing on developing and piloting an accreditation process and will examine the issues involved in creating an accrediting agency to implement a program accreditation process.

\section{Elements of Program Practices}

The US has been at the forefront of expanding access to college for young adults with ID as an outcome of advocacy efforts by their families [17] as well as research by academics (e.g., Becht et al. 2020 [7]) and efforts by politicians (e.g., Florida's comprehensive transition program legislation). Even so, PSE programs are not universally available and new programs emerge each year and existing programs continue to evolve. Currently, there are a wide range of practices and services. Common program elements of inclusive PSE include academic access, career development, campus membership, independent living skill development, and self-determination skills. Self-determination skills tend to be an umbrella program component through which other program elements are designed and implemented. Students can access a range of college opportunities including credit versus non-credit-bearing courses, programs at two- and four-year institutions, and residential and non-residential options [39]. 
Students may participate in personally selected college courses that are not only of interest to them but also may be aligned with a career goal. Students also often make use of supports such as academic peer mentors, educational coaches, or ambassadors. Mentors and coaches are paid or unpaid college students who provide one to one or small group learning support. Supports of this nature are designed to both enhance student learning in college courses and to increase student academic independence over time [40,41]. Students with ID, like traditionally matriculating students with disabilities, may also receive accommodations in their classes coordinated through the college or university Accessibility Services Office (ASO). These accommodations include, but are not limited to, interpreters, extended testing time, and note takers. Academic access for students with ID is intended to result not only in the opportunity to participate in competitive integrated employment, but to do so in a chosen career path. As such, a tenet of many PSE programs is career development. Additionally, campus communities that demonstrate the values and beliefs reflective of an inclusive campus provide students with ID opportunities such as participation clubs and activities (e.g., intramural sports, academic or personal interest clubs), and the ability to develop and enhance independent living skills in on or off-campus housing. A wide array of college experiences allows students to develop career readiness, improve social skills, and potentially build lifelong personal and professional relationships.

Self-determination largely serves as a foundational component of many PSE programs. Self-determination, in sum, means an individual has the skills, belief, and opportunity to be the primary causal agent in her/his/their lives [42]. Students in PSE settings exhibit self-determined behavior when they engage in acts of self-advocacy, for example, a student explaining her disability to an instructor and describing her learning needs. Self-determination is also reflected in such acts as problem solving, choice making, goal setting, and when making other personal life decisions about activities to engage in. One study of 251 first-year college and university students with ID found the number of social activities students engaged in predicted their scores on autonomy, self-realization, and overall self- determination [43].

College also results in an opportunity to learn and practice soft skills. Soft skills include competencies such as teamwork, communication, conflict resolution, dependability, and adaptability. Both self-determination and soft skills are necessary to achieve adult life goals regardless of disability status [44]. While programs and their respective practices continue to evolve, the growth of PSE programs and services for students with ID have led to increased opportunities to conduct research and advancements in policy development in this field.

\section{Inclusive Higher Education Research, Policy and Funding}

As the opportunity to access higher education grows for students with ID, so too does the opportunity to explore its participants and components, and its impact and outcomes through research. Early reviews of literature on this topic noted the dearth of studies on limited ranges of topics, with the preponderance of articles providing program descriptions $[15,45]$. More recently, the prevalence of research on higher education for students with ID has increased and focus of these studies has broadened substantially. From 2010 to 2016, there were 60 articles published in peer-reviewed journals, an average of 8.6 studies per year [46]. In the subsequent 5 years (2017-2021), there were twice as many, 120 peer-reviewed articles, for an average of 24 per year. Studies have also gone beyond the early focus on program descriptions and have begun to explore a wider range of issues and topics.

Researchers have sought to capture the perspectives of faculty and staff involved in these higher education initiatives [35,36]. A positive shift in the attitudes and levels of acceptance from higher education faculty is evident in these studies [35,36,47], but the need for training and support remain an important part of effectively engaging faculty to meet the diverse learning needs of college students with ID. Student experiences have 
also been studied, looking at students' motivations [42]; growth in self-determination [43]; and student course and employment experiences [28]. Analysis of student course enrollments, and the associated outcomes of those learning experiences, are also emerging in the literature [48].

Another growing aspect of emerging research is focused on documenting the impact PSE experiences have on the employment status of students with ID while they are enrolled in college, and after they complete their college learning $[13,27,33,39,49,50]$. Given the historically poor employment outcomes experienced by people with ID, these studies serve two important purposes. First, they demonstrate students with ID can access courses related to a career interest and, simultaneously, participate in career exploration, and in some cases, paid work experiences. Secondly, these studies demonstrate the impact various employment components of a student experience (e.g., career exploration, paid and unpaid work-based learning) as well as access to inclusive coursework have on students' employment status when they complete PSE, and on their longer-term employment outcomes. One study on students with ID enrolled in TPSID-funded IHE programs found those who took only inclusive classes, participated in campus events, had prior paid work experience, and participated in volunteering and/or community service were more likely to earn at or above minimum wage during their most recent year in the TPSID program [50]. Another study also on students enrolled in TPSID-funded programs found students with ID who obtained a paid job while enrolled in college were almost 15 -fold more likely to have a paid job at exit than those who did not [13].

Other areas of research, specifically those focusing on individuals with ID who receive support from VR, offer additional support for the supposition that higher education is an effective pathway to employment success [27]. Data on recipients of VR services are collected nationally each year in the Rehabilitation Services Administration's Case Service Report (RSA-911) dataset. These data have been analyzed recently by several researchers exploring the impact PSE has had on the employment outcomes of those receiving VR services $[9,27,33]$.

Findings from these studies show VR clients with ID who experienced PSE were more than twice as likely to be employed and have increased earnings compared to their counterparts who had not had access to PSE [27]. Positive impacts were found for adult participants of PSE [9,33] and for transition aged youth participating in PSE [51]. PSE for people with ID has also been found to be both cost-effective (cheaper than other services) and cost-efficient (pays for itself over time) [52]. Despite these strong indications that PSE is positively linked to better employment outcomes, there has been inconsistent support for using VR services to support students with ID to access PSE. Much of the disparity is due to inconsistent interpretation of federal guidance by local and state leaders when developing policy and legislation [18].

In addition to federal legislation such as the HEOA and the ADA, state governments also have developed legislation related to PSE initiatives for students with ID. In 2019, 27 pieces of state legislation were identified, some establishing task forces and commissions, others related to funding for developing and evaluating such programs or establishing scholarships [53]. For example, in 2014 the Massachusetts Task Force on Higher Education for Students with Intellectual Disabilities and Autism Spectrum Disorder (ID/ASD) was convened by the House and Senate Co-Chairs of the Joint Committee on Higher Education in the state of Massachusetts. This taskforce created a report describing higher education opportunities for students with ID/ASD nationally and statewide and included specific findings and recommendations to increase access to inclusive higher education and ensure citizens with ID/ASD have equal opportunity to reach their potential.

The state of Colorado passed a law (Senate Bill 196: Inclusive Higher Education Act) authorizing funding for a pilot inclusive higher education program for students with IDD resulting in new programs at two four-year universities and one community college. Another law of significant impact, the Florida Postsecondary Comprehensive Transition Program (FPCTP) Act, was passed in the state of Florida. It established the Florida Center 
for Students with Unique Abilities and provided $\$ 8$ million in funding and has established, to date, 19 programs for students with ID at IHEs throughout the state.

State and federal funds to support program development have made a significant impact on the availability of PSE options for students with ID, but these do not address the need for fiscal support to help students and their families afford the tuition and fees for IHE attendance. Programs seeking to assist students from low-income families may apply to the Federal Student Aid office to become an approved CTP, making federal grant and work-study funds available to eligible students. For example, one requirement of programs funded through the Florida FPCTP legislation is that the program become an approved CTP prior to the culmination of available state funding. In addition to federal student aid and limited potential funding from VR related to employment supports, students may also seek scholarships and consider the use of other disability related fiscal supports like those available through federal programs such as Medicaid. For example, Medicaid Home and Community Based Services (HCBS) waivers in some states can be used to pay for peer support career services, transportation, tuition, and fees [54]. State policies may impact the nature of these supports or how students' needs and services must be documented to qualify for the use of such funding.

\section{Conclusions}

Higher education offers great opportunities for social and intellectual exploration and builds capacity for future employment. With the advent of funding due to legislation and policy changes in the US, students with ID are beginning to reap these same benefits from higher education. College and university students with ID are now able to access courses, earn credits, explore career pathways, and earn credentials. They are increasingly leaving higher education with employment, beginning to grow in their independent living capacity, and have satisfying social lives. These desirable outcomes are the result of IHEs recognizing the potential in these individuals and creating access to systems and services that both include and support them. The emergence of students with ID on college and university campuses has also led to significant changes in federal and state legislation and policies, and the need for increased collaboration among other disability organizations. Lastly, it has created fertile ground for new research exploring what works, and why, in and among the students, peers, and faculty involved in these learning experiences. The progress evident in the US may provide useful guidance and resources for stakeholders in other countries interested in furthering inclusive higher education for their citizens with ID.

Author Contributions: Conceptualization, M.G., L.L.D.III and Z.W.; writing-original draft preparation M.G. and L.L.D.III; writing - review and editing, M.G., L.L.D.III and Z.W. All authors have read and agreed to the published version of the manuscript.

Funding: Funds for this project were provided, in part, by a grant from the Office of Postsecondary Education, US Department of Education Award Number P407B100002.

Institutional Review Board Statement: Not applicable.

Informed Consent Statement: Not applicable.

Conflicts of Interest: The authors declare no conflict of interest.

\section{References}

1. U.S. Bureau of Labor Statistics. Available online: https:/ /www.bls.gov/careeroutlook/2016/data-on-display/education-matters. htm?view_ful (accessed on 1 November 2021).

2. Carnevale, A.P.; Strohl, J.; Ridley, N.; Gulish, A. Three Educational Pathways to Good Jobs: High School, Middle Skills, and Bachelor's Degree; Georgetown University Center on Education and the Workforce: Washington, DC, USA, 2018.

3. Blumenstyk, G. By 2020, They Said, 2 Out of 3 Jobs Would Need More Than a High-School Diploma. Were They Right? The Edge: The Chronicle of Higher Education. Available online: https:/ / www.chronicle.com/newsletter/the-edge/2020-01-22 (accessed on 1 November 2021).

4. Bureau of Labor Statistics. Persons with a Disability: Labor Force Characteristics. 2021. Available online: https://www.bls.gov/ news.release/disabl.nr0.htm (accessed on 1 November 2021). 
5. Wagner, M.; Newman, L.; Cameto, R.; Garza, N.; Levine, P. After High School: A First Look at the Postschool Experiences of Youth with Disabilities. A Report from the National Longitudinal Transition Study-2 (NLTS2); SRI International: Menlo Park, CA, USA, 2005. Available online: https:/ / files.eric.ed.gov / fulltext/ED494935.pdf (accessed on 1 November 2021).

6. Lipscomb, S.; Haimson, J.; Liu, A.Y.; Burghardt, J.; Johnson, D.R.; Thurlow, M.L. Preparing for Life after High School: The Characteristics and Experiences of Youth in Special Education. Findings from the National Longitudinal Transition Study 2012; Comparisons across disability groups: Full report (NCEE 2017-4018); Department of Education, Institute of Education Sciences, National Center for Education Evaluation and Regional Assistance: Washington, DC, USA, 2017; Volume 2.

7. Becht, K.; Roberts-Dahm, L.D.; Meyer, A.; Giarrusso, D.; Still-Richardson, E. Inclusive postsecondary education programs of study for students with intellectual disability. J. Postsecond. Educ. Disabil. 2020, 33, 63-79.

8. Southward, J.D.; Kyzar, K. Predictors of competitive employment for students with intellectual and/or developmental disabilities. Educ. Train. Autism Dev. Disabil. 2017, 52, 26-37.

9. Miller, S.C.; Sax, C.L.; Tucker, M.S. Examining associations between postsecondary education, earnings, and provision of college and university training related to individuals with intellectual and developmental disabilities served by vocational rehabilitation. J. Rehabil. 2019, 85, 22-34.

10. Dukes, L.L., III; Hart, D. Barriers and solutions to creating inclusive higher education options for individuals with intellectual disabilities. In Proceedings of the Division on Autism and Developmental Disabilities Conference, Clearwater Beach, FL, USA, 20-22 January 2021.

11. Butler, L.N.; Sheppard-Jones, K.; Whaley, B.; Harrison, B.; Osness, M. Does participation in higher education make a difference in life outcomes for students with intellectual disability? J. Vocat. Rehabil. 2015, 44, 295-298. [CrossRef]

12. Jahoda, A.; Banks, P.; Dagnan, D.; Kemp, J.; Kerr, W.; Williams, V. Starting a New Job: The Social and Emotional Experience of People with Intellectual Disabilities. J. Appl. Res. Intellect. Disabil. 2009, 22, 421-425. [CrossRef]

13. Grigal, M.; Papay, C.; Smith, F.; Hart, D.; Verbeck, R. Experiences that predict employment for students with intellectual and developmental disabilities in federally funded higher education programs. Career Dev. Transit. Except. Individ. 2019, 42, 17-28. [CrossRef]

14. Jones, M.; Boyle, M.; May, C.; Prohn, S.; Updike, J.; Wheeler, C. Building Inclusive Campus Communities: A Framework for Inclusion. Boston, MA: University of Massachusetts Boston, Institute for Community Inclusion. Think Coll. Insight Brief. 2015, 26, $1-6$.

15. Neubert, D.A.; Moon, M.S.; Grigal, M.; Redd, V. Postsecondary educational practices for individuals with mental retardation and other significant disabilities: A review of the literature. J. Vocat. Rehabil. 2001, 16, 155-168.

16. Jones, L.A.; Moe, R. College education for mentally retarded adults. Ment. Retard. 1980, 18, 59.

17. Grigal, M.; Hart, D.; Paiewonsky, M. Think College: Postsecondary Education Options for Students with Intellectual Disabilities; Brookes Publishing: Baltimore, MD, USA, 2010.

18. Lee, S.; Rozell, D.; Will, M. Addressing the Policy Tangle: Students with Intellectual Disability and the Path to Postsecondary Education, Employment and Community Living; Inclusive Higher Education Committee: Washington, DC, USA, 2018.

19. Grigal, M.; Hart, D.; Weir, C. A Survey of Postsecondary Education Programs for Students with Intellectual Disabilities in the United States. J. Policy Pract. Intellect. Disabil. 2012, 9, 223-233. [CrossRef]

20. Higher Education Opportunity Act of 2008, PL 110-315, 20 U.S.C. §§1001 et seq. 2008. Available online: https:/ /www.govinfo. gov/content/pkg/PLAW-110publ315/pdf/PLAW-110publ315.pdf (accessed on 9 September 2021).

21. Higher Education Act of 1965, PL 89-329, 20 U.S.C. §§1001 et seq. 1965. Available online: https:/ /www.govinfo.gov/content/ pkg/COMPS-765/pdf/COMPS-765.pdf (accessed on 9 September 2021).

22. Individuals with Disabilities Education Act of 1997, PL 105-17, 20 U.S.C. § 1400 et seq. 1997. Available online: https: / www. govinfo.gov/content/pkg/PLAW-105publ17/html/PLAW-105publ17.htm (accessed on 9 September 2021).

23. Boyle, M. Federal Financial Aid for Students with Intellectual Disabilities; Issue No. 16; University of Massachusetts Boston, Institute for Community Inclusion: Boston, MA, USA, 2012.

24. Section 504 of the Rehabilitation Act of 1973, PL No. 93-112, 87 Stat. 394. 1973. Available online: https://www.govinfo.gov/ content/pkg/STATUTE-87/pdf/STATUTE-87-Pg355.pdf\#page=1 (accessed on 9 September 2021).

25. Americans with Disabilities Act of 1990. PL No. 101-336, 42 U.S.C. § 12101. 2016. Available online: https: / / www.govinfo.gov/ content/pkg/COMPS-803/pdf/COMPS-803.pdf (accessed on 9 September 2021).

26. Americans with Disabilities Act Amendments Act of 2008. PL No. 110-325, 122 Stat. 3553. 2008. Available online: https: //www.ada.gov/pubs/adastatute08.htm (accessed on 9 September 2021).

27. Sannicandro, T.; Parish, S.; Fournier, S.; Mitra, M.; Paiewonsky, M. Employment, income, and SSI effects of postsecondary education for people with intellectual disability. Am. J. Intellect. Dev. Disabil. 2018, 123, 412-497. [CrossRef]

28. Grigal, M.; Hart, D.; Papay, C.; Wu, X.; Lazo, R.; Smith, F.; Domin, D. Annual Report of the Cohort 2 TPSID Model Demonstration projects (Year 5, 2019-2020); University of Massachusetts Boston, Institute for Community Inclusion: Boston, MA, USA, 2021.

29. Grigal, M.; Papay, C.; Weir, C.; Hart, D.; McClellan, M. Characteristics of higher education programs enrolling students with intellectual disability in the United States. Inclusion. 2021. Advance Online Publication. Available online: http://aaidd.org/ publications/journals/articles-accepted-for-publication (accessed on 9 September 2021).

30. National Center for Education Statistics. Undergraduate Retention and Graduation Rates. 2020. Available online: https: / / nces.ed.gov/programs/coe/indicator_ctr.asp (accessed on 9 September 2021). 
31. Winsor, J.; Timmons, J.C.; Butterworth, J.; Migliore, A.; Domin, D.; Zalewska, A.; Shepard, J. StateData: The National Report on Employment Services and Outcomes through 2018. Available online: https://scholarworks.umb.edu/ici_pubs/132/ (accessed on 9 September 2021).

32. National Core Indicators. 2018-2019 In-Person Survey: Work. National Association of State Directors of Developmental Disabilities Services and Human Services Research Institute. 2019. Available online: www.nationalcoreindicators.org/upload/ core-indicators/Employment_4_16.pdf (accessed on 9 September 2021).

33. Smith, F.; Grigal, M.; Shepard, J. Impact of Postsecondary Education on Employment Outcomes of Youth with Intellectual Disability Served by Vocational Rehabilitation; Think College Fast Facts, 18; University of Massachusetts Boston, Institute for Community Inclusion: Boston, MA, USA, 2018.

34. Plotner, A.J.; Marshall, K.J. Postsecondary education programs for students with an intellectual disability: Facilitators and barriers to implementation. Intellect. Dev. Disabil. 2015, 53, 58-69. [CrossRef]

35. Taylor, A.; Domin, D.; Papay, C.; Grigal, M. "More dynamic, more engaged": Faculty perspectives on instructing students with intellectual disability in inclusive courses. J. Incl. Postsecond. Educ. 2021, 3, 1-24. [CrossRef]

36. Gilson, C.; Gushanas, C.; Li, Y.F.; Foster, K. Defining inclusion: Faculty and students' attitudes regarding postsecondary education for students with intellectual and developmental disabilities. Intellect. Dev. Disabil. 2020, 58, 65-81. [CrossRef] [PubMed]

37. Grigal, M.; Hart, D.; Weir, C. Postsecondary education for people with intellectual disability: Current issues and critical challenges. Inclusion 2013, 1, 50-63. [CrossRef]

38. Think College National Coordinating Center Accreditation Workgroup. Report on Model Accreditation Standards for Higher Education Programs for Students with Intellectual Disability: Progress on the Path to Education, Employment, and Community Living; University of Massachusetts Boston, Institute for Community Inclusion: Boston, MA, USA, 2021.

39. Avellone, L.; Camden, J.; Taylor, J.; Wehman, P. Employment outcomes for students with intellectual disabilities in postsecondary education programs: A scoping review. J. Postsecond. Educ. Disabil. 2021, 34, 223-238.

40. Jones, M.; Goble, Z. Creating effective mentoring partnerships for students with intellectual disabilities on campus. J. Policy Pract. Intellect. Disabil. 2012, 9, 270-278. [CrossRef]

41. Blumberg, R.; Daley, R. The use of peer mentors to facilitate the inclusion of youth with intellectual and developmental disabilities in postsecondary education. NADD Bull. 2009, 12, 16-21.

42. Gelbar, N.; Madaus, J.W.; Dukes, L.L., III; Faggella-Luby, M.; Volk, D.T.; Monahan, J. Self-Determination and college students with disabilities: Research trends and construct measurement. J. Stud. Aff. Res. Pract. 2020, 57, 163-181. [CrossRef]

43. Shogren, K.A.; Wehmeyer, M.L.; Shaw, L.A.; Grigal, M.; Hart, D.; Smith, F.A.; Khamsi, S. Predictors of self-determination in postsecondary education for students with intellectual and developmental disabilities. Educ. Train. Autism Dev. Disabil. 2017, 53, 146-159.

44. Grigal, M.; Madaus, J.W.; Dukes, L.L., II; Hart, D. (Eds.) Navigating the Transition from High School to College for Students with Disabilities; Routledge Publishing: New York, NY, USA, 2018.

45. Thoma, C.A.; Lakin, K.; Carlson, D.; Domzal, C.; Austin, K.; Boyd, K. Participation in postsecondary education for students with intellectual disabilities: A review of the literature 2001-2010. J. Postsecond. Educ. Disabil. 2011, 24, 175-191.

46. Papay, C.; Grigal, M. A review of the literature on postsecondary education for students with intellectual disability 2010-2016: Examining the influence of federal funding and alignment with research in disability and postsecondary education. J. Postsecond. Educ. Disabil. 2019, 32, 427-443.

47. Burgin, E.C.; DeDiego, A.C.; Gibbons, M.M.; Cihak, D.F. "Smiling and ready to learn": A qualitative exploration of university audit classroom instructors' experience with students with intellectual disabilities. J. Postsecond. Educ. Disabil. 2017, 30, 359-372.

48. Papay, C.; Grigal, M.; Hart, D.; Kwan, N.; Smith, F.A. Predictors of inclusive course enrollments in higher education by students with intellectual and developmental disabilities. Intellect. Dev. Disabil. 2018, 56, 458-470. [CrossRef]

49. Domin, D.; Taylor, A.B.; Haines, K.A.; Papay, C.K.; Grigal, M. "It's not just about a paycheck": Perspectives on employment preparation of students with intellectual disability in federally funded higher education programs. Intellect. Dev. Disabil. 2020, 58, 328-347. [CrossRef] [PubMed]

50. Qian, X.; Johnson, D.R.; Smith, F.A.; Papay, C.K. Predictors associated with paid employment status of community and technical college students with intellectual disability. Am. J. Intellect. Dev. Disabil. 2018, 123, 329-343. [CrossRef] [PubMed]

51. Rast, J.E.; Roux, A.M.; Shattuck, P.T. Use of Vocational Rehabilitation Supports for Postsecondary Education Among TransitionAge Youth on the Autism Spectrum. J. Autism Dev. Disord. 2018, 50, 2164-2173. [CrossRef] [PubMed]

52. Cimera, R.E.; Thoma, C.A.; Whittenburg, H.N.; Ruhl, A.N. Is getting a postsecondary education a good investment for supported employees with intellectual disability and taxpayers? Inclusion 2018, 6, 97-109. [CrossRef]

53. Jernudd, I.; Nagaraj, S.; Mueller, S.; Rozell, D. State Policy Actions Supporting Higher Education for Students with Intellectual and Developmental Disabilities; Think College Insight Brief Issue No. 42; University of Massachusetts Boston, Institute for Community Inclusion: Boston, MA, USA, 2019.

54. Parisi, P.; Landau, J. Use of Medicaid Waivers to Support Students with Intellectual Disability in College; Think College Insight Brief Issue No. 40; University of Massachusetts Boston, Institute for Community Inclusion: Boston, MA, USA, 2019. 